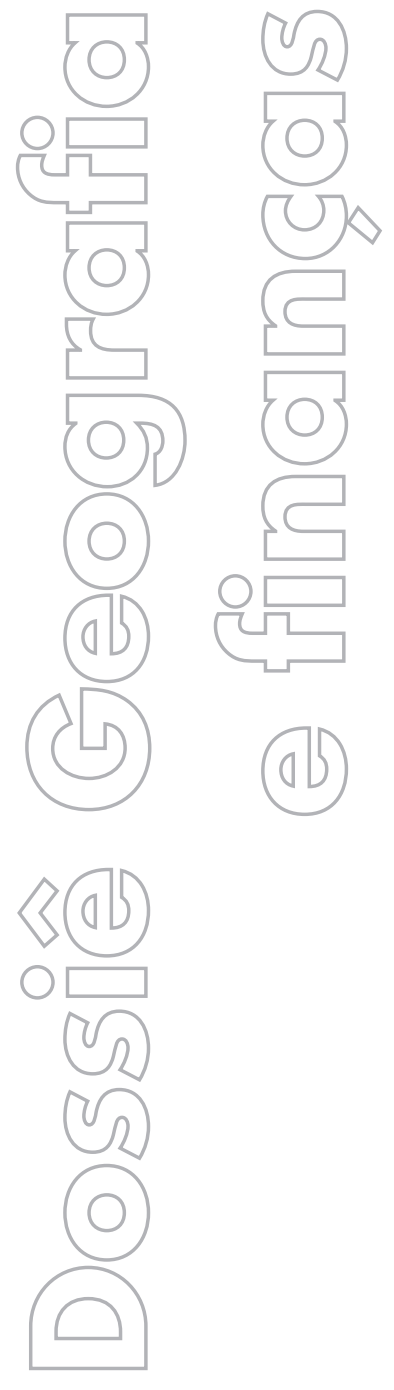

revista

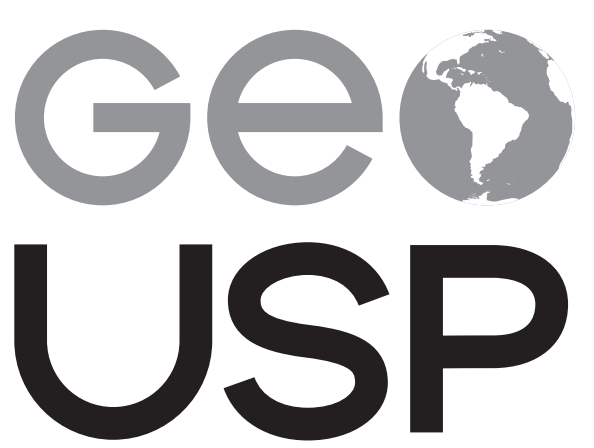

espaço e tempo

Volume $21 \cdot n^{\circ} 2$ (2017)
O correspondente bancário como estratégia de reorganização de redes bancárias e financeiras no Brasil

Leila Christina Duarte Dias UFSC

p. $384-396$

Como citar este artigo:

DIAS, L. C. D. O correspondente bancário como estratégia de reorganização de redes bancarias e financeiras no Brasil. Geousp - Espaço e Tempo (Online), v. 21, n. 2, p. 384-396, agosto. 2017. ISSN 2179-0892.

Disponível em: < http://www.revistas.usp.br/geousp/ article/view/137839>. doi: 10.11606/issn.2179-0892. geousp.2017.137839.

\section{(c) $(1) \Theta$}

Este artigo está licenciado sob a Creative Commons Attribution 4.0 License. 


\title{
O correspondente bancário como estratégia de reorganização de redes bancárias e financeiras no Brasil
}

\section{Resumo}

Este trabalho objetiva trazer elementos para discutir a crescente complexidade das redes bancárias e financeiras no Brasil analisando seu processo de reorganização nas últimas décadas e a invenção do correspondente bancário, objeto hibrido que combina serviço, tecnologia de comunicação e produto. Adquirindo outros bancos e sociedades de crédito para cumprir seus objetivos, os grupos financeiros têm presença no território garantida pelos correspondentes bancários - agentes comerciais e milhares de pequenos escritórios de contabilidade conectados às sedes dos bancos por plataformas tecnológicas que permitem prestar serviços. As operações de crédito e de arrendamento mercantil foram os serviços mais usados nos correspondentes bancários em 2016, chamando atenção para o processo de endividamento crescente dos mais pobres e idosos.

Palavras-chave: Geografia das finanças. Rede bancária. Rede financeira. Correspondente bancário. Crédito consignado.

\section{Banking correspondents: a strategy for reorganizing banking and financial services in Brazil}

\begin{abstract}
This paper aims to bring elements to discuss the growing complexity of banking and financial networks in Brazil, analyzing its reorganization process in the last decades and the invention of the banking correspondent, a hybrid object that combines service, communication technology and product. Acquiring other banks and credit companies to fulfill their objectives, the presence of the financial groups in the territory is guaranteed by the banking correspondents - commercial agents and thousands of small accounting offices connected to the seats of the banks by technological platforms that allow to render the services. Loan operations were the most used service in correspondent banking in 2016, drawing attention to the growing indebtedness process of the poorest and the elderly.
\end{abstract}

Keywords: Geography of finance. Banking network. Financial network. Banking correspondent. Consigned credit. 


\section{Introdução}

Nas duas últimas décadas, a literatura sobre a geografia das finanças não cessa de crescer, chamando a atenção para a necessidade de a abordagem geográfica instrumentalizar o debate sobre o processo de financeirização (Martin, 1999; Sokol, 2007; Contel, 2009; Dias, 2006; Dias; Lenzi, 2009; Silveira, 2011; Valencia, 2013). Apesar do crescente consenso de que as instituições financeiras e os mercados financeiros são atores cada vez mais importantes, moldando a vida econômica, social e cultural contemporânea, French, Leyshon e Wainwright (2011) identificaram pelo menos duas maneiras principais de como a ideia de financeirização vem sendo mobilizada pelos cientistas sociais. Na primeira, ela tem sido utilizada como descritor de ampla transformação na economia e na sociedade, na qual o setor financeiro e os mercados financeiros passaram a ocupar posição dominante ou quase dominante em países como EUA e Reino Unido. Na segunda, a financeirização foi empregada para descrever os processos e os efeitos do crescente poder dos valores financeiros e das tecnologias sobre as corporações, os indivíduos e as famílias.

Longe de eliminar a importância dos lugares nos processos financeiros, a mundialização financeira não tornou a geografia imaterial: pelo contrário, influenciada por contextos históricos e institucionais, a localização geográfica continua a demarcar quem tem acesso a quais serviços financeiros e a que preço, conforme demonstrou Dymski (2009) em contundente crítica à tese de O'Brien sobre o "fim da geografia". Com base no exemplo da crise do subprime nos EUA, Dymski mostrou que a vulnerabilidade às crises financeiras economicamente devastadoras varia ao longo do espaço nacional e subnacional, e que os empréstimos predatórios iniciaram em áreas mais pobres onde residem minorias étnicas raciais.

No Brasil, a abordagem sociológica e a geográfica estão presentes na reflexão sobre as complexas conexões entre finanças, sociedade, política e território (Minella, 200la, 200lb; Grun, 2004; Von Mettenheim, 2005; Dias; Lenzi, 2009; Creuz, 2013). No pioneiro artigo "Concentração bancária e os centros de gestão do território", Corrêa (1989) chamava a atenção para o relativo desinteresse dos geógrafos brasileiros pelo tema das finanças. Analisando o período compreendido entre 1961 e 1985, mostrou como o processo de concentração dos bancos comerciais no país se caracterizou pela redução do número de centros de gestão do território - cinquenta e três cidades deixam de abrigar sedes de bancos nesse período - e pela clara definição da metrópole paulista como principal centro financeiro do país. Nos anos 1990, as pesquisas de Lia Machado apontaram as relações entre o comércio ilícito de drogas e a integração mundial do sistema financeiro, e o papel que o território e as fronteiras dos Estados nacionais assumiam nesse processo (Machado, 1996, 1998). Largamente inspirados nos aportes teóricos de Milton Santos, os trabalhos de María Laura Silveira e de Fábio Contel vêm mostrando como os tempos locais e regionais são cada vez mais substituídos pelos tempos nacionais ou globais, quando famílias e indivíduos passam a contrair dívidas e a comprar produtos financeiros que alteram o ritmo da reprodução cotidiana de suas vidas. Para esses autores, as ações individuais e coletivas perdem cada vez mais seu caráter orgânico nos lugares em que efetivamente ocorrem; a creditização do território ou a "hipercapilaridade" do acesso ao crédito resulta numa racionalidade vertical, eminentemente financeira, que estaria impondo mais uma solidariedade organizacional que uma solidariedade orgânica ao sistema de ações do espa- 
ço brasileiro (Contel, 2007, 2009; Silveira, 2009, 2011). Com base em sua dissertação de mestrado e em sua tese de doutorado, Sandra Videira $(1999,2006)$ vem analisando a disseminação espacial dos bancos estrangeiros no território brasileiro, chamando a atenção para as lógicas locacionais e os modos de gestão das grandes corporações multilocalizadas, organizando também um pequeno núcleo de pesquisa na Universidade Estadual do Centro Oeste, no Paraná.

Um campo de pesquisa tem-se constituído progressivamente, trazendo ao debate as relações entre a globalização financeira e a soberania dos Estados nacionais, as conexões entre as finanças globais e os territórios regional e local, o desenvolvimento desigual e a reorganização espacial de redes bancárias e financeiras.

Este trabalho objetiva trazer elementos para discutir a crescente complexidade das redes bancárias e financeiras no Brasil. A primeira parte apresenta breve relato do processo de reorganização das redes dos maiores bancos privados nas últimas décadas, enquanto a segunda analisa a invenção do correspondente bancário em suas dimensões normativas, tecnológicas e econômicas. As considerações finais sintetizam os principais resultados e introduzem um caminho possível para analisar as finanças em nosso campo de conhecimento.

\section{Reorganização espacial de redes de grandes bancos privados}

Temos acompanhado na pesquisa a reorganização espacial das redes dos grandes bancos privados presentes no Brasil - nacionais e estrangeiros - e concluímos que é no encontro de ações empreendidas em diferentes escalas espaciais que os sistemas financeiro e bancário aqui se reorganizam. A ação dos atores hegemônicos internacionais - instituições, governos e banqueiros - acelera o processo de centralização das instituições financeiras por meio de fusões e incorporações. Interlocutor de primeira grandeza com os atores internacionais, o Banco Central do Brasil produz normas que de certo modo adaptam o sistema financeiro à "opinião" internacional. Os banqueiros nacionais e suas associações de classe integram a suas ações os mecanismos que operam na escala internacional, buscando também ampliar a concentração de capital por meio de fusões e incorporações e exercem influência muito superior àquela exercida por outros atores sociais sobre empresas e governo (Dias, 2006, 2011; Dias; Lenzi, 2009).

$\mathrm{Na}$ mesma medida em que os diversos países foram criando novos sistemas de normas para regulamentar o mercado financeiro e bancário, e a concorrência entre as instituições alcançou escala planetária, países periféricos e semiperiféricos da América Latina iniciaram reformas econômicas e financeiras a partir de 1985.' Foi nesse contexto que se inscreveu o processo de desregulamentação iniciado em 1988, quando o BC, por meio da Resolução n. 1.524 daquele ano, facultou aos bancos comerciais, aos bancos de investimento, aos bancos de desenvolvimento, às sociedades de crédito imobiliário e às sociedades de crédito, financiamento e investimento, a organização de uma única instituição financeira com personalidade jurídica própria, autorizando a criação dos bancos múltiplos ou universais. Ao mesmo tempo, o sistema de cartas patentes e de pontuação foi extinto, autorizando empresas comerciais e industriais a ingressar e concorrer no sistema bancário. Num primeiro momento, essa reorga-

1 Wallerstein (1979) formula os conceitos de países centrais, periféricos e semiperiféricos como três possibilidades diferentes de inserção na economia-mundo. Segundo o autor, os países semiperiféricos (entre os quais inclui o Brasil) atuam como zona periférica de países centrais e como países centrais de algumas áreas periféricas. 
nização institucional engendrou significativo crescimento no número de bancos que operavam no país. De pequeno e de médio porte, novos bancos foram constituídos como resultado da transformação de corretoras e financeiras em bancos múltiplos (Cerqueira; Amorim, 1997). Em consequência, o número de bancos mais do que duplicou em apenas dois anos, passando de 104 bancos comerciais em dezembro de 1988, a 215 bancos comerciais e múltiplos em 1990 (BCB, [s.d.]a). Essa trajetória de crescimento só foi interrompida após a implantação do Plano Real em 1994, quando o número de bancos não cessou de decrescer. Como explicar essa inversão de tendência?

O sistema financeiro, e particularmente o bancário, beneficiaram-se do cenário inflacionário, presente na economia brasileira desde a década de sessenta. Os bancos lucravam com as receitas obtidas pelo floating (recursos em trânsito) e com o financiamento do desequilibrio das contas públicas. Os planos econômicos de combate à inflação - Plano Cruzado (1986), Plano Verão (1989) e Planos Collor (1990 e 1991) - mostraram as dificuldades para o sistema bancário vigente manter-se numa conjuntura de estabilidade da moeda. A baixa capacidade competitiva dos bancos ficou evidente com o fim do uso das receitas inflacionárias que majoravam lucros e financiavam investimentos. A implantação do Programa Brasileiro de Estabilização Econômica (Plano Real) em 1994 inaugurou uma longa série de planos econômicos que deram continuidade ao processo de reorganização iniciado em 1988. Interlocutor de primeira grandeza com os atores internacionais, o Banco Central do Brasil (BC) criou progressivamente um conjunto de normas, por meio de resoluções e programas específicos, que redesenharam o quadro institucional no qual operavam os bancos. Em primeiro lugar, recomendou a adaptação das instituições financeiras aos princípios do Acordo da Basileia, dispondo sobre a obrigatoriedade de manter o patrimônio líquido em valor compatível com o grau de risco das operações ativas das instituições financeiras. Em segundo lugar, após uma sucessão de intervenções e liquidações que envolveram vinte e dois bancos em menos de dezoito meses, o BC implantou em 1995 o Programa de Estímulo à Reestruturação e ao Fortalecimento do Sistema Financeiro Nacional (Proer), que regulou a aquisição de bancos com problemas de solvência.

As ações de saneamento implantadas pelo Banco Central a partir de 1994 - liquidações, intervenções e administrações especiais - assim como os processos de fusão e incorporação, implicaram importantes movimentos de transferência de controle de instituições numa lógica que se caracteriza pela concentração bancária: entre 1994 e 2010, o número de bancos comerciais e múltiplos diminuiu continuamente no país, passando de 244 para 156, valor que permanece inalterado até 2017 (BCB, [s.d.]c).

Mudanças nas estruturas patrimoniais e operacionais, incluindo fusões e incorporações, e no padrão de rentabilidade (Paula; Marques, 2004) configuraram processos adaptativos à desregulamentação do sistema financeiro em escala internacional. Mudanças espaciais nas redes de agências bancárias constituíram também processo adaptativo às novas condições econômico-políticas vigentes. Os bancos planejaram e realizaram movimentos, inclusive espaciais, visando a alcançar um objetivo, mantendo posições relativas favoráveis a futuras ações. Assim, a partir da segunda metade dos anos 1980, condicionantes externos e internos mudaram a trajetória do sistema bancário, o que demandou nova geografia, caracterizada pela retração de agências bancárias no interior de todas as macrorregiões e, simultaneamente, expansão nas 
maiores regiões metropolitanas do país, especialmente São Paulo e Rio de Janeiro. Em outras palavras, uma adaptação espacial às novas condições macro e microeconômicas (Dias; Lenzi, 2009). Nos últimos anos, o processo de concentração espacial de agências vem constituindo a principal estratégia locacional dos maiores bancos privados nacionais e internacionais no país. Contudo, as grandes redes privadas, como Bradesco, Itaú-Unibanco e Santander não desistiram de seu domínio sobre o espaço, e essa nova geografia não foi tolerada por muito tempo, levando bancos a inventar ou reinventar a figura do correspondente bancário, um objeto hibrido que combina serviço, tecnologia de comunicação e produto, resultado de uma forma superior de inteligência financeira, - como diria Milton Santos (1996) sobre essa capacidade das firmas de inventar novos produtos sob o domínio do capitalismo financeiro.

\section{Reinvenção do correspondente bancário e expansão de redes}

Mudanças normativas, econômicas e espaciais estão articuladas num só conjunto cuja base tecnológica encontra-se nos avanços na capacidade de tratar informações e transmiti-las de um lugar a outro do planeta. Jayo (2010) sintetizou as principais periodizações propostas - no Brasil e no exterior - sobre a evolução no uso de tecnologias de informação (TI) pelos bancos, propondo a expressão "ondas de inovação" em lugar de fases, etapas e períodos; a ideia de onda chama a atenção para o caráter cumulativo no uso dessas tecnologias (Jayo, 2010). A primeira onda iniciou em meados dos anos $1960 \mathrm{com}$ a automação do back office por meio de sistemas de processamento centrais, seguida pela automação das agências (segunda onda), pela automação fora das agências (terceira onda), e pela chegada das aplicações tecnológicas às instalações dos usuários (quarta onda) (Jayo, 2010). Assim, limitada inicialmente à escala da agência, a automação dos caixas eletrônicos ultrapassou esse limite agências e se disseminou pelos espaços urbanos, permitindo a difusão dos serviços de autoatendimento. Desde 1995, a introdução do home banking significou o uso doméstico dos serviços, que não cessa de crescer: entre 1998 e 2008, o número de transações bancárias pela Internet passou de 38,7 milhões para 7,93 bilhões (Transações [...], 2009; Agência Estado [...], 2000). $\bigcirc$ uso de aplicativos de bancos para celulares e tablets - mobile banking - superou pela primeira vez em 2016 o internet banking e assumiu a primeira posição como canal mais utilizado no país para operações bancárias. ${ }^{2}$ A evolução do uso das TIs pelos bancos nos últimos anos sinaliza a emergência de uma quinta onda de inovação, caracterizada por "modelos de distribuição de serviços bancários intermediados por agentes de outros setores, que já têm relacionamento com a clientela a ser atingida" (Jayo, 2010, p. 29). Jayo esclarece que essa quinta onda de inovação surgiu de um conjunto de avaliações sobre a necessidade de "direcionar estratégias para o atendimento da base da pirâmide social, historicamente com pouco acesso a canais e serviços bancários" (Jayo, 2010, p. 29). Clientes de renda média e alta já estariam sendo bem atendidos, e, a partir de então, o crescimento dos bancos demandaria a inserção da clientela de baixa renda, potencialmente consumidora de serviços financeiros. Enquanto em países da Ásia e da África bancos e operadoras de telefonia móvel desenvolveram tecnologias de informação que viabilizaram o acesso a serviços bancários

2 Segundo a pesquisa divulgada em junho de 2017 pela Federação Brasileira dos Bancos (Febraban) (Alvarenga, 2017). 
pelos telefones celulares, no Brasil o modelo mais difundido foi o do correspondente bancário, resultado da parceria de distribuição de serviços financeiros entre bancos e agentes não bancários (Jayo, 2010).

Embora parte da legislação que regulamenta os correspondentes bancários não seja propriamente nova - as primeiras regulamentações datam da década de 1970 -, foi a partir de 1999 que um conjunto de Resoluções do BC organizou esse tipo de atendimento. Se num primeiro tempo os correspondentes bancários atenderam à necessidade do governo federal de criar mecanismos de transferência de renda para as famílias mais pobres, por meio do Bolsa Escola e de outros programas sociais lançados a partir de 2001, logo os bancos viram nesse objeto híbrido uma dupla oportunidade: reduzir o fluxo de pessoas no interior das agências e fechar agências em lugares menos lucrativos.

A utilização da rede de atendimento da Empresa Brasileira de Correios e Telégrafos pelo Bradesco (2002 a 2012) e pelo Banco do Brasil (a partir de 2012) talvez seja o exemplo mais conhecido desse serviço: sob o nome de Banco Postal, são oferecidos serviços de abertura de contas, recebimento de contas e de títulos e tributos, pedido de cartão e talão de cheque, pagamento de salários e benefícios, fornecimento de saldos e extratos, depósitos, saques e transferências e recepção e encaminhamento de pedidos de empréstimo e financiamento. Presente em mais de $94 \%$ dos municípios brasileiros, o Banco Postal constitui a única alternativa bancária em mais de 1.600 municípios (Correios, [s.d.]), trazendo para dentro do sistema financeiro e bancário volume considerável de recursos que têm origem em pequenos salários, pensões e aposentadorias do INSS recebidos pelas populações de baixa renda.

O contrato de correspondente pode ter como objeto uma ampla gama de atividades de atendimento com o intuito de oferecer produtos e serviços de responsabilidade da instituição contratante a seus clientes, como: recepção e encaminhamento de propostas de abertura de contas de depósitos à vista, a prazo e de poupança; recebimentos, pagamentos e transferências eletrônicas visando à movimentação de contas de depósitos de titularidade de clientes; recebimentos e pagamentos de qualquer natureza e outras atividades decorrentes da execução de contratos e convênios de prestação de serviços; execução ativa e passiva de ordens de pagamento cursadas por intermédio da instituição contratante por solicitação de clientes e usuários, além de recepção e encaminhamento de propostas referentes a operações de crédito e de arrendamento mercantil de concessão da instituição contratante; execução de serviços de cobrança extrajudicial, relativa a créditos de titularidade da instituição contratante ou de seus clientes; e recepção e encaminhamento de propostas de fornecimento de cartões de crédito de responsabilidade da instituição contratante (Resolução 3.954, de 24 de fevereiro de 2011 [BCB, 201lb]).

O Gráfico 1 representa a evolução do número de pontos de atendimento de correspondentes bancários nos serviços mais utilizados, mostrando que nem todos têm igual magnitude de uso nem o mesmo ritmo de crescimento. Entre 2008 e 2016, as operações de crédito e de arrendamento mercantil (tipo E) foram o serviço mais utilizado nos correspondentes bancários, enquanto o fornecimento de cartões de crédito de responsabilidade das instituições financeiras (tipo F) foi o serviço que mais cresceu (247\%); os serviços de abertura de contas correntes e de poupança, recebimentos e pagamentos de qualquer natureza, além de outras atividades 
decorrentes da execução de contratos e convênios de prestação de serviço, como pagamento de benefícios previdenciários e de programas sociais (tipos A, B e C) cresceram em ritmo mais lento do que os relativos às operações de crédito. ${ }^{3}$

\section{Gráfico 1 - Brasil: pontos de atendimento de correspondentes por tipos de serviços mais usados, em em 2008 e 2016}

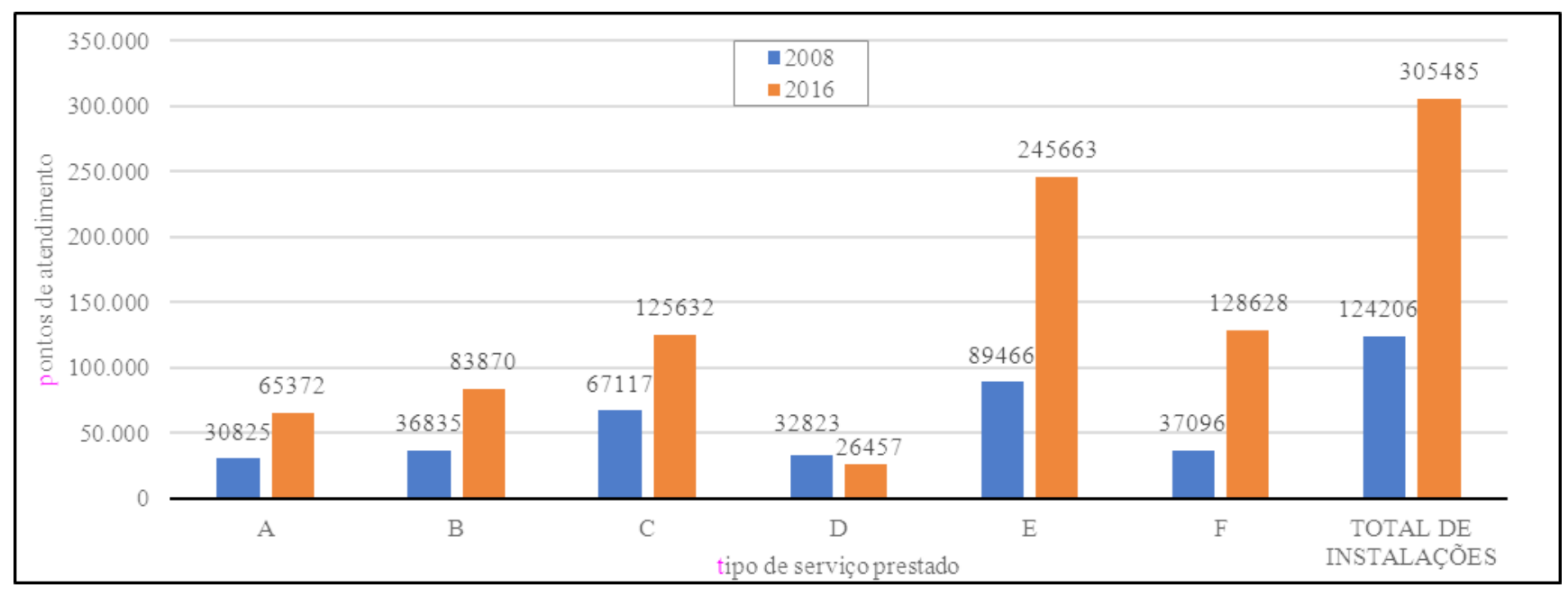

\begin{tabular}{|c|c|c|c|c|c|}
\hline \multicolumn{6}{|c|}{ legenda } \\
\hline A & $\begin{array}{l}\text { recepção e encaminhamento de pro- } \\
\text { postas de abertura de contas de de- } \\
\text { pósito à vista, a prazo e de poupança } \\
\text { mantidas pela instituição contratante }\end{array}$ & C & $\begin{array}{l}\text { recebimentos e pagamentos de } \\
\text { qualquer natureza e outras ativi- } \\
\text { dades decorrentes de contratos } \\
\text { e convênios de prestação de ser- } \\
\text { viços mantidos pela instituição } \\
\text { contratante com terceiros }\end{array}$ & $E$ & $\begin{array}{l}\text { recepção e encaminhamento de } \\
\text { propostas referentes a operações } \\
\text { de crédito e de arrendamento } \\
\text { mercantil de concessão da insti- } \\
\text { tuição contratante }\end{array}$ \\
\hline B & $\begin{array}{l}\text { realização de recebimentos, paga- } \\
\text { mentos e transferências eletrônicas } \\
\text { visando à movimentação de contas } \\
\text { de depósito de titularidade de clientes } \\
\text { mantidas pela instituição contratante }\end{array}$ & D & $\begin{array}{l}\text { execução ativa e passiva de or- } \\
\text { dens de pagamento cursadas } \\
\text { por intermédio da instituição } \\
\text { contratante por solicitação de } \\
\text { clientes e usuários }\end{array}$ & $\mathrm{F}$ & $\begin{array}{l}\text { recepção e encaminhamento de } \\
\text { propostas de fornecimento de } \\
\text { cartões de crédito de responsabi- } \\
\text { lidade da instituição contratante }\end{array}$ \\
\hline
\end{tabular}

organização: A autora, com base em informações dos meses de dezembro de 2008 e 2016 (BCB, [s.d.]b).

Em dezembro de 2016, 269 instituições financeiras contavam com correspondentes presentes em 305.485 instalações distribuídas pelo território brasileiro, enquanto a rede bancária contava com 22.547 agências (BCB, [s.d.]d). Um olhar para o organograma das maiores instituições financeiras que operam com correspondentes detecta um labirinto de redes de associações entre bancos e sociedades de crédito, financiamento e investimento; ${ }^{4}$ o banco, como unidade empresarial, não constitui o principal agente desse processo. $\bigcirc$ Bradesco ilustra essa ideia: enquanto o Banco Bradesco controla 12,5\% das instalações de correspondentes bancários no país, prestando todos os tipos de serviços, três outros bancos do grupo Bradesco - Banco Alvorada, Banco Losango e Banco Bradesco Financiamento, especializados nos empréstimos pessoais e no crédito direto ao consumidor, controlam mais $9,8 \%$ de correspondentes. Na mesma direção, o Banco Santander

3 Um mesmo ponto de atendimento pode ser conveniado a mais de uma instituição financeira.

4 Em 2016, a revista Valor Grandes Grupos publicou o organograma das maiores instituições financeiras no país. Das 200 maiores, deu também o organograma da participação acionária. 
controla 1,3\% das instalações e opera com todos os tipos de serviços, enquanto as empresas Aymoré Crédito e Financiamento, Banco Olé Bonsucesso Consignado, Banco RCI, Banco Bandepe e Banco PSA Finance do Brasil - pertencentes ao Grupo Financeiro Santander - controlam 7\% das instalações, atuando prioritariamente nas operações de crédito e de arrendamento mercantil (BCB, [s.d.]b). É o grupo econômico financeiro que coordena as atividades de diferentes pessoas jurídicas na busca de ganhos de escala e de escopo, minimizando custos e riscos e se beneficiando também do conhecimento de bancos pequenos e médios que se especializaram, desde o início dos anos 2000, na concessão da modalidade de crédito nomeada como "crédito consignado em folha de pagamento", que permite o desconto de parcelas de empréstimos e financiamentos diretamente nas folhas de pagamento de trabalhadores formais e aposentados e pensionistas do Instituto $\mathrm{Na}$ cional de Seguro Social (INSS). Mais uma vez assistimos a um processo de reinvenção no universo das finanças, quando o crédito consignado em folha de pagamento, criado pela Lei n. 6.445 (Brasil, 1977), e pouco usado nas décadas seguintes, é renormatizado por meio da Medida Provisória 130 (Brasil, 2003b), transformada na Lei n. 10.820 (Brasil, 2003a) três meses depois; que permitiu a celebração de acordos entre instituições financeiras, empresas e entidades sindicais (Moretti, 2006).

Estudo do Banco Central concluiu que em todas as macrorregiões brasileiras cresceu, entre 2004 e 2011, a participação das operações de crédito consignado no conjunto das operações de crédito para pessoas físicas; servidores públicos, ativos e inativos, e aposentados e pensionistas do INSS contrataram 85,6\% do total de empréstimos; e que, no universo dos aposentados e pensionistas, 57\% receberam benefício de até um salário-mínimo, e 87\% parcelaram o empréstimo em 49 a 60 meses (BCB, 2011a). Os idosos constituem o público alvo das campanhas publicitárias (Moretti, 2006), e esse consumidor, mais vulnerável em razão das fragilidades físicas e emocionais advindas do envelhecimento, se endivida por desinformação, por assédio de familiares e por abusos praticados pelas instituições financeiras e seus representantes (Porto, 2014; Doll; Cavallazzi, 2016).

\section{Considerações finais}

Atualmente, as instituições financeiras e bancárias são bem mais complexas do que aquelas dos anos 1980, especialmente pela construção de redes mais longas e conectadas, integrando uma miríade de agentes bancários e não bancários. Adquirindo outros bancos e sociedades de crédito para cumprir seus objetivos, a presença dos grupos financeiros no território é garantida por agentes comerciais e por milhares de pequenos escritórios de contabilidade conectados às sedes dos bancos por plataformas tecnológicas que permitem prover os serviços.

Num contexto de maior concentração bancária, os grupos econômicos buscaram economias de escala e escopo, infraestruturas que dessem suporte às operações financeiras e de capital humano. Ao mesmo tempo, inovaram, ampliando seu alcance espacial numa escala sem precedentes por meio de correspondentes bancários, reafirmando assim o quanto o domínio do espaço constitui fonte de poder para instituições bancárias e financeiras. Estudos acadêmicos e matérias jornalísticas empresariais indicam a emergência de um modelo brasileiro de correspondente bancário único, tanto pelo alcance, escala e qualidade dos serviços prestados quanto pelas novas plataformas tecnológicas que possibilitam a provisão dos serviços (Diniz; Pozzebon; Jayo, 2008), além de disseminar esse conceito para os demais países latino-americanos (Abud Junior, 2008). 
Nosso trabalho mostrou que as operações de crédito e arrendamento mercantil foram o serviço mais usado nos correspondentes bancários em 2016. Pesquisas vêm chamando a atenção para o processo de endividamento crescente dos mais pobres e idosos, que acarreta na impossibilidade de pagar as dívidas e na consequente aquisição de novos empréstimos para quitar as dívidas não pagas.

O sociólogo e filósofo italiano Maurício Lazzarato argumenta que a relação devedor-credor intensifica os mecanismos de exploração e dominação em cada nível da sociedade. Na sua visão, dívida é central para entender o neoliberalismo, porque longe de ser uma ameaça para a economia capitalista, a dívida encontra-se no cerne do projeto neoliberal. Na obra The making of the indebted man (2012b), Lazzarato mostra que a dívida é acima de tudo uma construção política e que a relação credor-devedor é a relação social fundamental das sociedades ocidentais. Firmas (incluindo os bancos), Estados nacionais, famílias e indivíduos podem ser vistos, segundo esse autor, como homo debitor: de uma forma ou de outra estão sujeitos às relações credor-devedor e à disciplina dos mercados financeiros. Da crise das hipotecas podres nos EUA (subprime) ao crédito consignado no Brasil, a relação credor-devedor exprime, nas palavras de Lazzarato (2012a, p. 1), "uma relação de força entre os proprietários e os não proprietários dos títulos de capital. Somas enormes são transferidas dos devedores (a maioria da população) para os credores (bancos, fundos de pensão, empresas, famílias mais ricas".

Um dos significados originais da palavra finança está diretamente ligado a dívida - do francês da Idade Média (1400) -, finança era entendida como encerramento, liquidação de uma dívida (Online Etymology Dictionary, [s.d.]). Para Lazzarato, "economia da dívida" seria um termo mais apropriado do que "economia das finanças", apesar de todos os desafios que a falta de instrumentos teóricos para analisar essa "economia da dívida" e suas implicações possam significar. Seguindo as pistas de pesquisa abertas pelo trabalho de Lazzarato, mais do que a lógica das finanças, parece ser a lógica do endividamento generalizado que tem marcado todos os campos da vida social, em múltiplas escalas espaciais, renovando as questões de pesquisa em nosso campo do conhecimento.

\section{Referências}

ABUD JUNIOR, J. Cresce demanda por correspondentes bancários. Jornal Diebold, São Paulo, v. 17, maio 2008. Disponível em: http://www.diebold.com.br/dweb/M_JornalDiebold.asp. Acesso em: 9 jan. 2009.

AGÊNCIA ESTADO. Bancos investem em operações pela Internet. O Estado de S. Paulo, São Paulo, 5 jun. 2000. Economia e Negócios. Disponível em: http://economia.estadao. com.br/noticias/geral,bancos-investem-em-operacoes-pela-internet,20000605p7213. Acesso em 10 jul. 2017.

ALVARENGA, D. Mobile banking se torna meio mais usado para transações bancárias, diz Febraban. G1, 10 maio 2017. Disponível em: https://gl.globo.com/economia/seu-dinheiro/noticia/mobile-banking-se-torna-meio-mais-usado-para-transacoes-bancarias-diz-febraban.ghtml. Acesso em: 2 ago. 2017. 
BCB. BANCO CENTRAL DO BRASIL. Boletim regional, Brasilia, v. 5, n. 2, abr. 2011 la.

Resolução n. 3.954, de 24 de fevereiro de 2011. Altera e consolida as normas que dispõem sobre a contratação de correspondentes no país. Diário Oficial da União, Brasilia, DF, 25 fev. 2011b. Seção 1, p. 44-45. Disponível em: https://www.bcb.gov.br/pre/normativos/ busca/normativo.asp?tipo=resEano=2011Enumero=3954. Acesso em: 23 set. 2017.

Bancos Brasileiros após a Resolução 1.524, de 21.09.88, [s.d.]a. Disponívelem: http://www.bcb.gov.br/htms/deorf/e88-2000/texto.asp?idpai=RELSFN19882000. Acesso em: 3 jul. 2017.

Correspondentes no país, [s.d.]b. Disponível em: http://www.bcb.gov.br/fis/info/ correspondentes.asp. Acesso em: 11 jul. 2017.

Relação de instituições em funcionamento no país, [s.d.]c. Disponível em: http://www.bcb.gov.br/fis/info/instituicoes.asp. Acesso em: 4 set. 2017.

Relatório de Evolução do SFN, [s.d.]d. Disponível em: http://www.bcb.gov. br/?revsfn201612. Acesso em: 4 ago. 2017.

BRASIL. Lei n. 10.820, de 17 de dezembro de 2003. Dispõe sobre a autorização para desconto de prestações em folha de pagamento, e dá outras providências. Diário Oficial da União, Brasilia, DF, 18 dez. 2003a. Disponível em: http://www.planalto.gov.br/ccivil_03/leis/2003/L10.820.htm. Acesso em: 15 set. 2017.

. Medida Provisória n. 130, de 17 de setembro de 2003. Dispõe sobre a autorização para desconto de prestações em folha de pagamento, e dá outras providências. Diário Oficial da União, Brasilia, DF, 18 set. 2003b. Disponível em: http://www2.camara. leg.br/legin/fed/medpro/2003/medidaprovisoria-130-17-setembro-2003-497030-publicacaooriginal-1-pe.html. Acesso em: 15 set. 2017.

. Lei n. 6.445, de 4 de outubro de 1977. Dispõe sobre consignações em folha de pagamento de servidores civis, ativos e inativos, da Administração Federal direta e das autarquias federais e dá outras providências. Diário Oficial da União, Brasilia, DF, 5 out. 1977. Disponível em: http://www.planalto.gov.br/ccivil_03/leis/1970-1979/L6445. htm. Acesso em: 15 set. 2017.

CERQUEIRA, H. E. A.; AMORIM, W. A. Evolução e características do emprego no setor bancário. In: CARLEIAL, L.; VALLE, R. (Org.). Reestruturação produtiva e mercado de trabalho no Brasil. São Paulo: Hucitec, 1997. p. 399-418.

CONTEL, F. Espaço geográfico, sistema bancário e a hipercapilaridade do crédito no Brasil. Caderno CRH, Salvador, v. 22, n. 55, p. 119-134, 2009.

Território e finanças: técnicas, normas e topologias bancárias no Brasil. Tese (Doutorado em Geografia) - Faculdade de Filosofia, Letras e Ciência Humanas, Universidade de São Paulo, São Paulo, 2007.

CORREAA, R. L. Concentração bancária e os centros de gestão do território. Revista Brasileira de Geografia, Rio de Janeiro, v. 51, n. 1, p. 17-32, 1989. 
CORREIOS. Banco Postal, [s.d.]. Disponível em: https://www.correios.com.br/Para-governo/governo-estadual/solucoes-financeiras. Acesso em: 4 ago. 2017.

CREUZ, V. Renovadas articulações entre os circuitos da economia urbana através das finanças: especificidades de Buenos Aires e São Paulo. Boletim Campineiro de Geografia, Campinas, v. 3, n. 3, p. 491-510, 2013.

DIAS, L. C. Reorganização das redes bancárias no Brasil: concentração e expansão geográfica. In: MARTINS, C. A. et al. (Org.). Quintas urbanas: cidades e possibilidades. Rio Grande, RS: Ed. Furg, 2011. p. 25-42.

Por que os bancos são o melhor negócio no país? Hegemonia financeira e geografia das redes bancárias. In: ALBUQUERQUE, E. S. (Org.). Que país é esse? Pensando o Brasil contemporâneo. São Paulo: Globo, 2006. p. 27-62.

. La géographie du systèmebancaire au Brésil: mutations ettendances. In: PITTE, J. R.; SANGUIN, A. L. Géographie et liberté. Paris: L'Harmattan, 1999. p. 359-366. ; LENZI, M. H. Reorganização espacial de redes bancárias no Brasil: processos adaptativos e inovadores. Caderno CRH, Salvador, v. 22, n. 55, p. 97-117, 2009.

DINIZ, E. H.; POZZEBON, M.; JAYO, M. The role of ICT in improving microcredit: the case of correspondent banking in Brazil. Cahier du GReSI, Montreal, v. 8, n. 3, p. $1-23,2008$.

DOLL, J.; CAVALLAZZI, R. L. Crédito consignado e o superendividamento dos idosos. Revista Brasileira do Direito do Consumidor, São Paulo, v. 106, p. 309-342, 2016.

DYMSKI, G. A. The global financial customer and the spatiality of exclusion after the 'end of geography'. Cambridge Journal of Regions, Economy and Society, Cambridge, v. 2, p. 267-285, 2009.

FRENCH, S.; LEYSHON, A.; WAINWRIGHT, T. Financializing space, spacing financialization. Progress in Human Geography, London, v. 35, n. 6, p. 798-819, 2011.

GRUN. R. A sociologia das finanças e a nova geografia do poder no Brasil. Tempo Social, São Paulo, v. 16, n. 2, p. 151-176, 2004.

JAYO, M. Correspondentes bancários como canal de distribuição de serviços financeiros: taxonomia, histórico, limites e potencialidades dos limites de gestão de redes. Tese (Doutorado em Administração de Empresas) - Escola de Administração de Empresas, Fundação Getúlio Vargas, São Paulo, 2010.

LAZZARATO, M. A era do homem endividado. Le Monde Diplomatique, São Paulo, ano 5, n. 55, fev. 2012a.

The Making of the Indebted Man. Los Angeles: Semiotexte, 2012b.

MACHADO, L. O. Financial flows and drug trafficking in the Amazon basin. Unesco/Most - discussion paper 22, Paris, v. 1, p. 1-18, 1998. 
O comércio ilícito de drogas e a geografia da integração financeira: uma simbiose? In: CASTRO, I. et al. (Org.). Brasil: questões atuais da reorganização do território. Rio de Janeiro: Bertrand Brasil, 1996. p. 15-64.

MARTIN, R. Money and the space economy. Chichester: John Wiley \& Sons, 1999.

MINELLA, A. C. Globalização financeira e as associações de bancos na América Latina. In: ENCONTRO ANUAL DA ANPOCS, 25., 2001a, Caxambu, MG. Anais... Caxambu, MG, 200la. p. 1-27.

Hegemonia e controle financeiros no capitalismo contemporâneo. Cultura Vozes, Petrópolis, n. 4, p. 117-136, 200 lb.

MORETTI, S. A emergência de novos formatos organizacionais no sistema bancário brasileiro: um estudo preliminar sobre a geografia do crédito consignado. Monografia (Graduação em Geografia) - Centro de Filosofia e Ciências Humanas, Universidade Federal de Santa Catarina, Florianópolis, 2006.

ONLINE Etymology Dictionary. Disponível em: http://www.etymonline.com. Acesso em: 25 set. 2017.

PAULA, L. F; MARQUES, M. B. L. Tendências recentes da consolidação bancária no mundo e no Brasil. In: ENCONTRO NACIONAL DE ECONOMIA POLÍTICA, 9., 2004, Uberlândia, MG. Anais... Uberlândia, MG, 2004. p. 1-25.

PORTO, E. A. Evolução do crédito pessoal no Brasil e o superendividamento do consumidor aposentado e pensionista em razão do crédito consignado. Dissertação (Mestrado em Direito Econômico) - Centro de Ciências Jurídicas, Universidade Federal da Paraiba, 2014.

SANTOS, M. A natureza do espaço. São Paulo: Hucitec, 1996.

SILVEIRA, M. L. Crises e paradoxos da cidade contemporânea: os circuitos da economia urbana. In: PEREIRA, E. et al. As cidades e a urbanização no Brasil: passado, presente e futuro. Florianópolis: Insular, 2011. p. 62-82.

. Finanças, consumo e circuitos da economia urbana na cidade de São Paulo. Cadernos CRH, Salvador, v. 22, n. 55, p. 65-76, 2009.

SOKOL, M. Space of flows, uneven regional development and the geography of financial services in Ireland. Growth and Change, Hoboken, v. 38, p. 224-259, 2007.

TRANSAÇÕES bancárias pela internet crescem 14,4\%, diz Febraban. Época Negócios Online, 4 jun. 2009. Disponível em: http://epocanegocios.globo.com/Revista/ Common/0,,EMI76022-16357,00-TRANSACOES+BANCARIAS+PELA+INTE RNET+CRESCEM+DIZ+FEBRABAN.html. Acesso em: 10 jul. 2017.

VALENCIA, C. T. Sistema financiero y territorio: una perspectiva desde el conocimiento geográfico. In: CHÁVEZ TORRES, M.; CHECA ARTASU, M. (Ed.). El espacio en las ciencias sociales: geografía, interdisciplinariedad y compromiso. Zamora, ES: El Colegio de Michoacán, 2013. p. 381-405. 
VIDEIRA, S. L. A territorialização dos bancos estrangeiros no Brasil: o caso da rede do Santander. Tese (Doutorado em Geografia) - Faculdade de Ciências e Tecnologia, Universidade Estadual Paulista "Júlio de Mesquita Filho", Presidente Prudente, 2006.

Dinâmica espacial do sistema bancário no estado de São Paulo. Dissertação (Mestrado em Geografia) - Centro de Filosofia e Ciências Humanas, Universidade Federal de Santa Catarina, Florianópolis, 1999.

VON METTENHEIM, K. Commanding Heights: para uma sociologia política dos bancos federais brasileiro. Revista Brasileira de Ciências Sociais, São Paulo, v. 20, n. 58, p. 47-61, 2005.

WALLERSTEIN, I. The capitalist world-economy. Cambridge: Cambridge University Press/Paris: Maison des Sciences de l'homme, 1979. 